\title{
О ПРАВЕ СВИДЕТЕЛЯ НА АДВОКАТА: ВОПРОСЫ ТЕОРИИ И ПРАКТИКИ
}

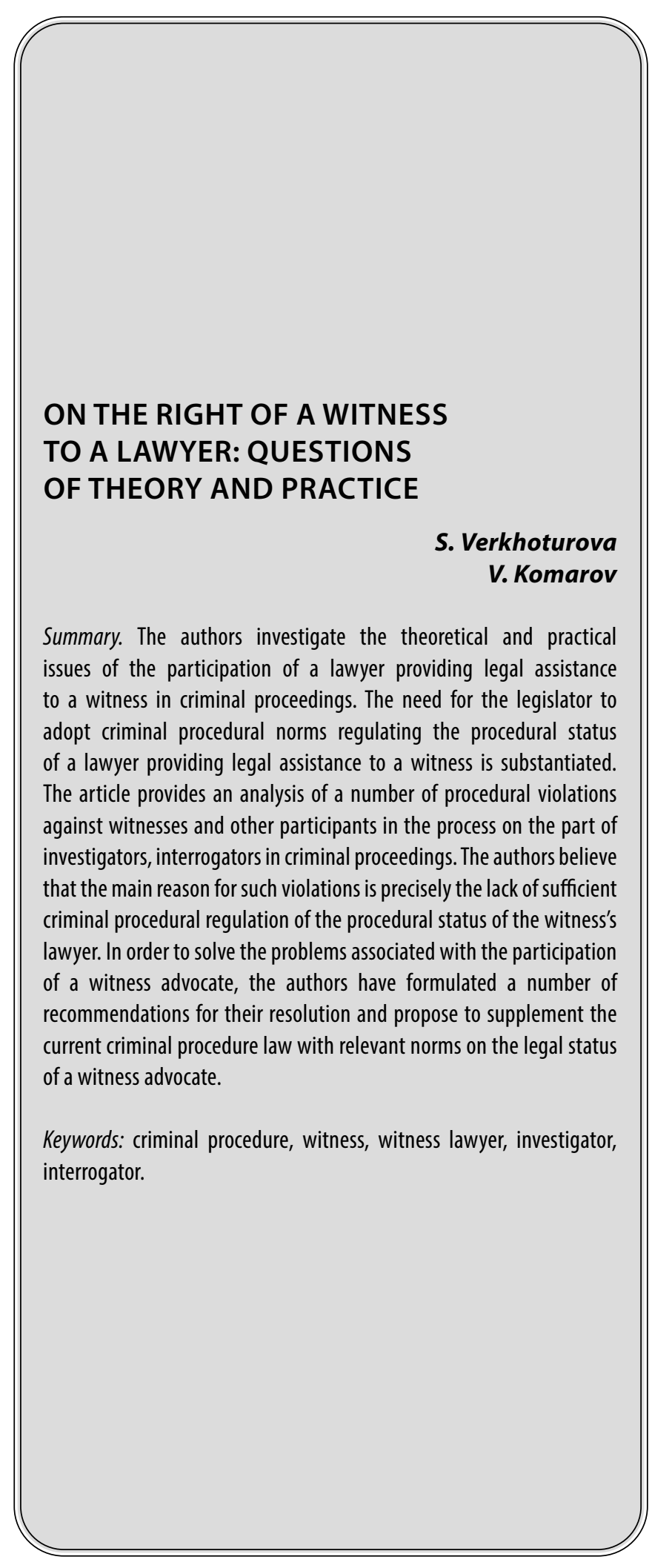

Верхотурова Светлана Владимировна К.ю.н., дочент, Тюменский государственный университет verxoturova00@mail.ru Комаров Вячеслав Борисович К.ю.н., дочент, Тюменский государственный университет; адвокат, коллегия адвокатов Уральского Федерального Округа специализированный филиал «Юрпрофи» 922471@mail.ru

Аннотация. Авторами исследуются теоретические и практические вопросы участия адвоката, оказывающего правовую помощь свидетелю в уголовном судопроизводстве. 0босновывается необходимость принятия законодателем уголовно-процессуальных норм, регламентирующих процессуальный статус адвоката, оказывающего свидетелю юридическую помощь. В статье приводится анализ ряда процессуальных нарушений в отношении свидетелей и иных участников процесса со стороны следователей, дознавателей при производстве по уголовному делу. Авторы считают, что основной причиной подобных нарушений является именно отсутствие достаточной уголовно-процессуальной регламентации процессуального статуса адвоката свидетеля. В целях решения проблем связанных с участием адвоката-свидетеля, авторы сформулировали ряд рекомендаций для их разрешения и предлагают дополнить действующий уголовно-процессуальный закон соответствующими нормами о правовом статусе адвоката свидетеля.

Ключевые слова: уголовный процесс, свидетель, адвокат свидетеля, следователь, дознаватель. 
$\Pi$ раво каждого гражданина на получение квалифицированной юридической помощи гарантируется Конституцией РФ (ст. 48), признается международно-правовыми актами и действующим уголовно-процессуальным законом, который уделяет повышенное внимание защите прав и законных интересов всех участников уголовного судопроизводства, в том числе и иных участников процесса, к которым относится свидетель [2].Следователь, дознаватель при производстве по уголовному делу обязаны не только разъяснить всем участникам процесса их процессуальные права, обязанности, ответственность, но и обеспечить реализацию этих прав путем создания определенных условий в ходе следственных и иных процессуальных действий.От эффективного обеспечения следователем (дознавателем) прав участников процесса в ходе предварительного расследования зависит не только качество следствия и дознания, но и результаты рассмотрения уголовного дела в суде. Нарушения прав участников процесса, в том числе, и на получение квалифицированной юридической помощи, приводят к признанию доказательств полученных в ходе расследования недопустимыми ${ }^{1}$. При этом, следует обратить внимание, что при производстве по уголовному делу могут нарушаться права не только заинтересованных участников стороны обвинения и стороны защиты, но и иных незаинтересованных участников процесса. Поэтому первостепенная задача следователя, дознавателя состоит не только в быстром и полном расследовании уголовного дела, но и в обеспечении прав всех участников процесса с целью достижение назначения уголовного судопроизводства (ст. 6 УПК РФ) [3].

Согласно ч. 1 ст. 56 УПК РФ, свидетелем является лицо, которому могут быть известны какие-либо обстоятельства, имеющие значение для расследования и разрешения уголовного дела и которое вызвано для дачи показаний (исключение составляют лица, перечисленные в ч. 3 ст. 56 УПК РФ). Из содержания данной статьи следует, что любое лицо может быть допрошены в качестве свидетеля и по любым фактическим обстоятельствам уголовного дела. В следственной практике известно немало случаев, когда лица, вовлеченные в сферу уголовно-процессуальных отношений, мгновенно меняли статус свидетеля на статус подозреваемого, а затем на обвиняемого. Так, например,

\footnotetext{
1 Например, Верховный Суд Дагестана признал недопустимым доказательством показания свидетеля по уголовному делу, которые были получены при допросе без участия переводчика и адвоката для оказания юридической помощи (допрос проводился на одном языке, протокол составлен был уже на другом языке и подписан лицом не владеющим уголовным судопроизводством).См.: Апелляционное постановление Верховного Суда Республики Дагестан от 29 июля 2020 г. по делу № 221018/2020 // Судебные и нормативные акты Российской Федерации: сайт. URL: http://sudact.ru
}

нельзя отрицать тот факт, что в следственной практике встречаются ситуации, когда следователь (дознаватель) вызывает лицо на допрос в качестве свидетеля, допрашивает его, а позже выносит постановление о привлечении лица в качестве обвиняемого в порядке главы 23 УПК РФ. В таком случае, следователь, дознаватель без особого труда получают необходимые сведения о фактических обстоятельствах уголовного дела из уст свидетеля, который в силу своего процессуального положения обязан давать правдивые показания, и не может отказаться от дачи показаний (кроме показаний в отношении себя, п. 1 ч. 4 ст. 56).В дальнейшем, подобного рода свидетельские показания могут быть использованы против его интересов и указаны в обвинительном заключении.

Поэтому, неслучайно, законодатель предоставил право свидетелю как самостоятельному иному участнику процесса явиться на допрос с адвокатом (ч. 4 ст. 56 УПК РФ). Несмотря на то, что основным способом получения показаний свидетеля как вида доказательств является допрос, в отношении свидетеля могут производиться и другие следственные действия, например - очная ставка, обыск, выемка, проверка показаний на месте, следственный эксперимент, экспертиза, которые затрагивают его конституционные права, несмотря на то, что это прямо в законе не предусмотрено. В подтверждении сказанного, можно привести ряд судебных решений подтверждающих факт участия адвоката не только при допросе свидетеля, но и в иных следственных действиях с целью оказания ему правовой помощи [1]. При этом, анализ судебных решений позволяет сделать вывод, что суды в своих решениях не проводят различий между «адвокатом свидетеля как его представителем» и «адвокатом свидетеля, защищающим его интересы». В документах (постановлениях, определениях, приговорах) данные понятия используются как синонимы.

Анализ и изучение адвокатской практики показал, что при проведении следственных действий, функция адвоката сводится не только к представительству интересов свидетеля, но иногда к защите его интересов, а также его консультированию. Поэтому, считаем нецелесообразно, утверждать, что адвокат принимает участие только как «представитель свидетеля» или только как «защитник свидетеля», поскольку в любом случае, он оказывает правовую помощь свидетелю как иному участнику процесса. Представляется, что в данном случае следует говорить о самостоятельном участнике - адвокате свидетеля, в деятельности которого могут проявляться разные направления деятельности. Подобное положение адвоката свидетеля помогает при производстве по делу избежать разного рода разногласий (например, между свидетелем и следователем, 
между свидетелем и адвокатом, представляющим интересы противоположной стороны).

В силу своего процессуального положения, адвокат при производстве по делу в праве ходатайствовать о производстве разных следственных действий и принимать в них участие, если они направлены на получение сведений об обстоятельствах, указывающих на незаконность и необоснованность производства следователем, дознавателем процессуальных действий и принятых им решений в отношении свидетеля. Следует отметить, что в действующем уголовно-процессуальном законе никак не отражено содержание и время консультаций адвоката со свидетелем перед следственным действием и при его проведении. Представляется, что консультирование адвокатом свидетеля может иметь место и содержать какие-либо пояснения по юридическими тактическим вопросам проведения следственных действий. Полагаем, что данный пробел следует устранить и предусмотреть в законе возможность участие адвоката, оказывающему правовую помощь свидетелю во всех следственных действиях, производимых с его участием.

Далее, в действующем уголовно-процессуальном законе законодатель не определил статус адвоката свидетеля, в частности его процессуальные права. Так, в ч. 5 ст. 189 УПК РФ говорится о том, что если свидетель явился на допрос с адвокатом, приглашенным им для оказания юридической помощи, то адвокат присутствует на допросе и пользуется правами защитника, предусмотренные ч. 2 ст. 53 УПК РФ. Так, адвокат, приглашенный для оказания юридической помощи свидетелю вправе: консультировать свидетеля (в присутствии следователя); задавать вопросы свидетелю (с разрешения следователя); делать замечания в письменной форме по поводу правильности изложения записей в протоколе следственного действия; делать заявление о нарушениях прав и законных интересов свидетеля (по окончании допроса). Следователь (дознаватель) может отвести вопросы защитника, но обязан занести отведенные вопросы в протокол. Однако, не все права адвоката свидетеля нашли свое отражения в уголовно-процессуальном законе, например: право адвоката на ходатайства об объявлении перерыва для конфиденциального обсуждения каких-либо вопросов; право на отвод переводчика; право на удостоверение адвокатом факта отказа от подписания или невозможности подписания протокола следственного действия, право на получение копий протоколов следственных действий с участием свидетеля (кроме случаев необходимости обеспечения тайны следствия) и др.

По-прежнему, остается неурегулированным процессуальный порядок допуска адвоката свидетеля в уголовный процесс. Учитывая тот факт, что адвокатам требуется определенное время для подготовки при обращении свидетеля за юридической помощью до производства следственного действия (особенно, в случаях внезапной доставки лица для допроса или звонков от родственников с просьбой срочно выехать к следователю для оказания юридической помощи свидетелю), представляется, что следователь (дознаватель) должен заблаговременно во всех случаях оповестить свидетеля в повестке о его праве явиться на допрос с адвокатом. Это позволит свидетелю своевременно обратиться в соответствующее адвокатское образование за юридической помощью. Напомним, что лицо на допрос в качестве свидетеля может быть вызвано также с помощью средств связи, но каких именно законом точно не регламентировано, это может быть: телефонный звонок, письмо по электронной почте; смс - сообщение; с помощью социальных сетей и др. Если следователь (дознаватель) при вызове лица в качестве свидетеля не разъяснил ему право явиться на допрос с адвокатом, то свидетель об этом праве может и не знать, а значит, не сможет его реализовать в полной мере.

Как показывает практика, свидетели в большинстве случаев самостоятельно, по своей инициативе обращаются к адвокату и являются с ним на допрос, но не все из них знают, что они вправе также заявить ходатайство следователю (дознавателю)о приглашении адвоката с целью оказания ему правовой помощи. Данное право вытекает из прямо предусмотренного законом положения, согласно которому, свидетель не только вправе обжаловать действия и решения следователя (дознавателя), но и заявлять ходатайства. При этом, законодатель в статье 119 УПК РФ не упоминает прямо свидетеля в числе участников процесса, имеющих право заявлять ходатайства. Умалчивается и об обязательности удовлетворения такого рода ходатайства.

Законодатель не предусматривает возможность приглашения следователем, дознавателем адвоката на допрос свидетеля, который имеет финансовые трудности, либо не владеет языком уголовного судопроизводства, страдает физическими или психическими недостатками (в отличие от допроса подозреваемого, обвиняемого, когда государство гарантирует обязательное участие адвоката в таких случаях). Полагаем, поскольку такие свидетели не могут надлежащим образом самостоятельно осуществлять свои права, а их охраняемые интересы не могут быть обеспечены в полной мере следователю, дознавателю следует самостоятельно пригласить адвоката.

Остается неразрешенной проблема и по обеспечения прав несовершеннолетнего свидетеля (до 18 лет), который явился на допрос. В силу своего возраста 
и малого жизненного опыта он не отдает себе отчет в том, что при допросе ему может понадобиться помощь адвоката, который бы разъяснил и защитил его права. Поскольку несовершеннолетнее лицо изначально находится в неравном положении по сравнению с взрослыми участниками процесса, способными отстоять свои права самостоятельно, считаем, необходимым, предусмотреть в законе обязанность следователя (дознавателя) пригласить адвоката для оказания ему юридической помощи. Адвокат в таких случаях также может быть приглашен законным представителем несовершеннолетнего самостоятельно.

Полагаем, что явка свидетеля с адвокатом во всех случаях не должна рассматриваться следователем (дознавателем) как факт, уличающий вызванное лицо в совершении преступного деяния. Гарантией обеспечения данного права свидетеля служит возможность обжалование действия (бездействие) должностных лиц, производящих расследование уголовного дела прокурору или в суд. Так, согласно положениям, ст. ст. 123 и 125 УПК РФ, жалобу на процессуальные решения и действия (бездействие) дознавателя, следователя, руководителя следственного органа, прокурора вправе подать любой участник уголовного судопроизводства или иное лицо в той части, в которой производимые процессуальные действия и принимаемые процессуальные решения затрагивают его права и интересы.

В уголовно-процессуальном законе не отражен вопрос об этапах уголовного судопроизводства, на которых может принимать участие адвокат свидетеля, а в частности, законодатель не упоминает о праве очевидца пригласить адвоката на стадию возбуждения уголовного дела для оказания ему правовой помощи с момента начала осуществления процессуальных действий, затрагивающих его права и свободы (ст. 144 УПК РФ). Полагаем, поскольку на данном этапе судопроизводства статус многих участников процесса еще точно не определен, и они часто нуждаются в юридической помощи, очевидец (в случае приглашении его для дачи объяснений, проведения опроса) вправе пригласить адвоката. Данное право вытекает из положений Постановления Конституционного Суда РФ № 11-П от 27.06.2000 г., гарантировавшим юридическую помощь адвоката во всех случаях, когда права и свободы лица существенно затрагиваются или могут быть затронуты действиями и мерами в рамках уголовного преследования[5]. Верховный Суд РФ также пояснил, что в уголовном процессе, обеспечение права на защиту - один из ключевых принципов, поэтому реализация такого права обязательно должна быть предоставлена не только участникам процесса со стороны защиты, но и свидетелям, которые по своему статусу также могут представлять либо интересы стороны защиты, либо стороны обвинения [6].
Хотелось бы обратить внимание на непоследовательную позицию законодателя по вопросу участия адвоката при допросе свидетеля в судебном заседании. Несомненно, что адвокат свидетеля в суде должен быть гарантом соблюдения его законных прав и интересов. Например, если суду или участникам процесса непонятно содержание показаний свидетеля, то адвокат вправе разъяснить их или если суд, или стороны задают вопросы свидетелю, то адвокат поможет подготовить ответы на эти вопросы и др. Несмотря на то, что в законе не предусмотрено право адвоката присутствовать при допросе свидетеля в судебном заседании, суды обеспечивают данное право в полной мере.

Особый интерес вызывает вопрос об отводе адвоката свидетеля: «Может ли такой адвокат, оказывающий правовую помощи свидетелю (со стороны обвинения или защиты) одновременно осуществлять защиту обвиняемого в рамках одного уголовного дела?». Конституционный Суд РФ в своем определении ответил на данный вопрос и указал, что адвокат не может принимать участие в уголовном деле на стороне свидетеля, если до этого он оказывал (или оказывает) правовую помощь стороне по делу, интересы которой противоречат интересам свидетеля. В подобном случае может возникнуть конфликт интересов между свидетелем и иными участниками процесса. Для предотвращения такого конфликта, адвокату следует заявить отвод, а свидетель вправе пригласить для участия в допросе иного адвоката, не участвующего в данном деле для получения квалифицированной юридической помощи [4].

В адвокатской практике встречаются и другие ситуации, когда следователь (дознаватель) необоснованно (по надуманным основаниям) отказывается допросить, поочередно, одновременно явившихся, подозреваемого и свидетеля, который готов подтвердить позицию подозреваемого и тем самым опровергнуть имеющееся подозрение лица, в отношении которого возбуждено уголовное дело. В таких случаях следователь также отказывается допросить свидетеля в присутствии защитника подозреваемого под предлогом того, что между этим свидетелем и подозреваемым в будущем могут возникнуть противоречия, несмотря на то, что в настоящее время каких-либо разногласий между очевидцем и подозреваемым не имеется. Следователь выносит необоснованное решения об отводе адвоката, несмотря на то, что свидетель настаивает, чтобы юридическую помощь ему при допросе оказал именно тот адвокат, который, по этому же делу, защищает и подозреваемого. Представляется, что подобные действия органа предварительно расследования приводят к нарушению права на защиту законных интересов как свидетеля, так и подозреваемого. 
Конфликт интересов может возникнуть и в случае, когда адвокат по уголовному делу представляет интересы сразу нескольких свидетелей по одному делу, но спустя несколько месяцев предварительного расследования может сложиться ситуация, когда один из таких свидетелей меняет свой статус на статус подозреваемого или обвиняемого либо статус потерпевшего, и, соответственно, исходя из определения Конституционного Суда РФ, у органов предварительного расследования появляются основания для отвода адвоката от участия в деле. Представляется также, что один и тот же адвокат не может оказывать одновременно правовую помощь свидетелю и лицу, в отношении которого дело выделено в отдельное производство в связи с заключением с ним досудебного соглашения о сотрудничестве (ст. 56.1 УПК РФ).

На основе вышеизложенного полагаем, что законодателю следует в отдельной статье уголовно-процессуального закона прямо предусмотреть процессуальные права адвоката свидетеля как самостоятельного иного участника процесса, что положит конец дискуссиям среди исследователей и практиков по вопросу функции адвоката свидетеля «(представитель он или защитник в уголовном процессе?»). Четкая правовая регламентация в законе относительно процессуального статуса адвоката свидетеля будет способствовать эффективному обеспечению следователем (дознавателем) прав данного участника процесса при расследовании преступлений, а также получению достоверных доказательств и вынесению судом правосудных приговоров. Адвокаты в ходе опроса также пояснили, что действующий уголовно-процессуальный закон значительно ограничивает их права при оказании юридической помощи свидетелю по уголовному делу, поскольку отсутствует в действующем законе правовая регламентация процессуального статуса адвоката свидетеля, как, например, во многих странах СНГ'1.

На основе изложенного, представляется целесообразным, признать адвоката свидетеля самостоятельным иным участником процесса и внести следующие изменения в УПК РФ:

А) предусмотреть в главе 8 статью 56.2 УПК РФ «Адвокат свидетеля» следующего содержания:

\footnotetext{
Участие адвоката свидетеля и его процессуальный статус предусмотрен в уголовно-процессуальном законодательстве многих странах СНГ (например, в УПК РеспубликиБеларусь - ст. 60; УПК Азербайджанской Республики - ст. 105; УПК Республики Молдова ст. 92 и др.). См.: УПК Белоруссии URL: http://legislationline.org/ru/ documents/section/criminal-codes; УПК Азербайджана URL: http:// legisiationHne.org/ru/docurnents/section/crirnjnal-codes; УПК Молдавии URL: http://legislationline.org/ru/documents/section/criminal-codes.
}

1.Адвокат свидетеля приглашается свидетелем, его законным представителем, а также другими лицами по поручению или с согласия свидетеля.

2.Адвокат свидетеля вправе:

1) оказывать юридическую помощь свидетелю при производстве следственных действий сего участием;

2) в присутствии следователя консультировать свидетеля;

3) задавать с разрешения следователя вопросы;

4) делать письменные замечания по поводу правильности и полноты записей в протоколе;

5) делать заявления на нарушения прав и законных интересов свидетеля, которые заносятся в протокол.

6) ходатайствовать об объявлении перерыва для конфиденциального обсуждения каких-либо вопросов со свидетелем;

7) заявлять ходатайство об отводе переводчика;

8) удостоверять факта отказа от подписания или невозможности подписания протокола следственного действия свидетелем;

9) знакомиться с протоколами следственных действий, производимых с участием свидетеля;

10) получать копии протоколов следственных действий с участием свидетеля, за исключением случае ст. 161 УПК РФ.

3. Адвокат свидетеля обязан не разглашать сведения об обстоятельствах, ставших известными ему по уголовному делу, если он был предупрежден об этом в порядке ст. 161 настоящего Кодекса. За разглашение данных предварительного расследования адвокат свидетеля несет ответственность в соответствии со статьей 310Уголовного кодекса Российской Федерации.

Б) пункт бчасти 4 ст. 56 УПК РФ следует изложить в следующей редакции:

«ходатайствовать о приглашении адвоката для оказания юридической помощи, а также являться с адвокатом для производства следственных действий с его участием»;

В) часть 5 ст. 189УПК РФ изложить в следующей редакции: «Если свидетель явился с адвокатом для участия в допросе, то адвокат пользуется правами, предусмотренными частью второй статьи 56.2 настоящего Кодекса. 


\section{ЛИТЕРАТУРА}

1. Апелляционное постановление Приморского краевого суда РФ от 6 июля 2016 г. по делу № 22К-4097/2016; Апелляционное постановление Ставропольского краевого суда РФот 29 июля 2015 г. по делу № 22К-3966/2015 [Электронный ресурс] // Судебные и нормативные акты Российской Федерации: сайт. URL: http://sudact.ru (дата обращения 1 сентября2021 г.)

2. Конституция Российской Федерации (принята всенародным голосованием 12.12.1993) (с учетом поправок, внесенных Законами РФ о поправках к Конституции РФ от 30.12.2008 N6-ФК3, от 30.12.2008 N7-ФК3, от 05.02.2014 N2-ФК3, от 01.07.2020 N11-ФК3) // Собрание законодательства РФ, 01.07.2020, N31, ст. 4398.

3. Уголовно-процессуальный кодекс Российской Федерации от 18 декабря 2001 года № 174-Ф3: по сост. 27.11 .2021 г. // Собрание законодательства Российской Федерации. — 2001. - № 52 (ч.І).—- С. 4921.

4. Определение Конституционного Суда РФ от 15 октября 2018 г. N2518-0“06 отказе в принятии к рассмотрению жалобы гражданки Егоровой Валентины Ивановны на нарушение ее конституционных прав пунктом 3 части первой статьи 72 Уголовно-процессуального кодекса Российской Федерации// Доступ из справ - правовой системы «Консультант Плюс».

5. Постановление Конституционного Суда РФ от 27.06.2000 N11-П «По делу о проверке конституционности положений части первой статьи 47 и части второй статьи 51 Уголовно — процессуального кодекса РСФСР в связи с жалобой гражданина В.И. Маслова»// Доступ из справ — правовой системы «Консультант Плюс».

6. Постановление Пленума Верховного Суда РФ от 30.06.2015 N29 «0 практике применения судами законодательства, обеспечивающего право на защиту в уголовном судопроизводстве»// Доступ из справ — правовой системы «Консультант Плюс».

( С Верхотурова Светлана Владимировна ( verxoturova00@mail.ru ), Комаров Вячеслав Борисович ( $922471 @ m a i l . r u$ ).

Журнал «Современная наука: актуальные проблемы теории и практики»

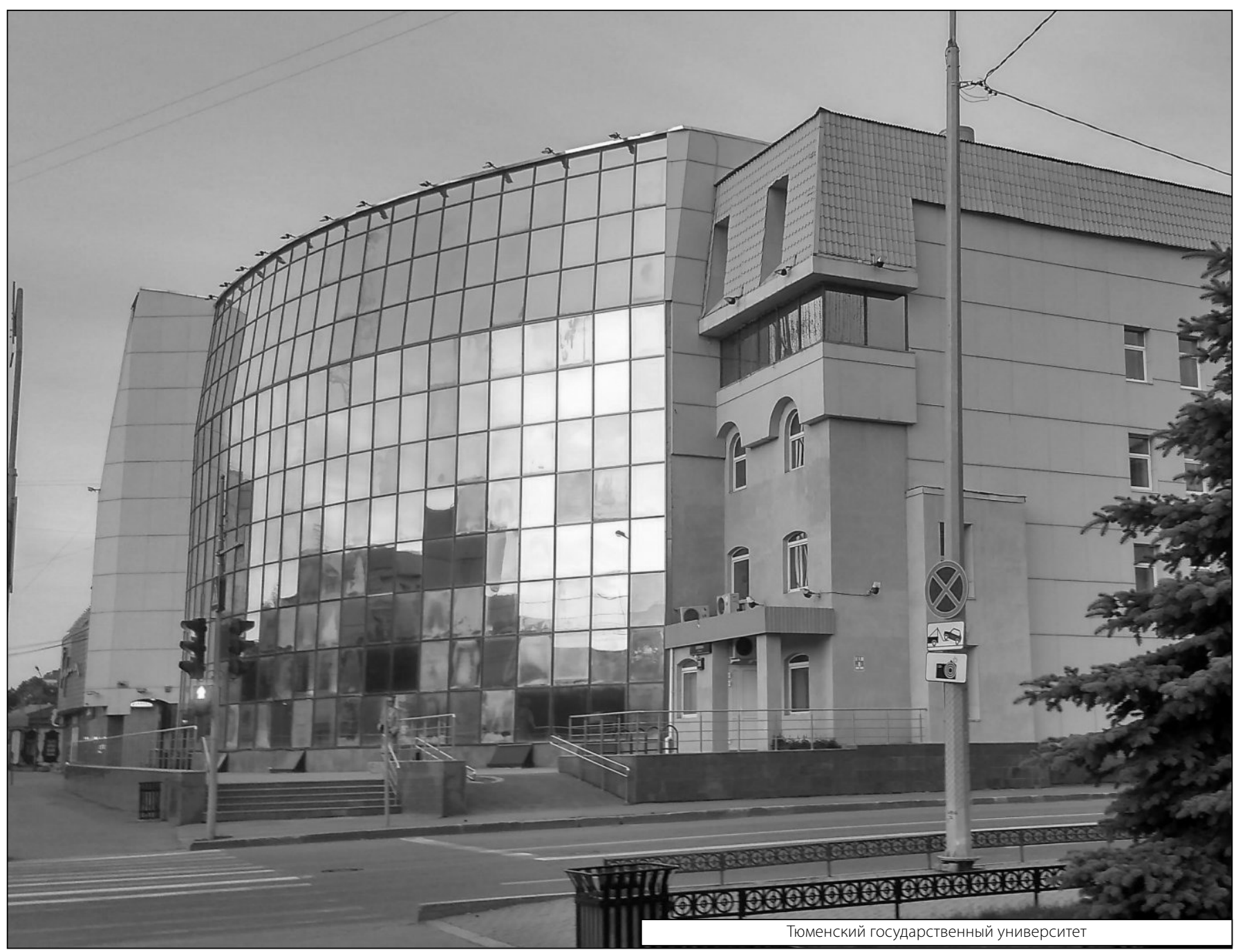

